\title{
PRACTICES FOLLOWED DURING HOME QUARANTINE/ ISOLATION FOR COVID-19 PANDEMIC AMONG URBAN POPULATION OF ROHTAK, HARYANA
}

\section{Dr. B. M. Vashisht \\ Dr. Dhriti Bapna* \\ Dr. Arup Saha}

Professor, Dept. of Community Medicine, Pt. B.D. Sharma Post Graduate Institute of Medical Sciences, Rohtak.

Senior Resident, Dept. of Community Medicine, Pt. B.D. Sharma Post Graduate Institute of Medical Sciences, Rohtak. ${ }^{*}$ Corresponding Author

Senior Resident, Dept. of Community Medicine, Pt. B.D. Sharma Post Graduate Institute of Medical Sciences, Rohtak.

Junior Resident, Dept. of Community Medicine, Pt. B.D. Sharma Post Graduate Institute of Medical Sciences, Rohtak.

Junior Resident, Dept. of Community Medicine, Pt. B.D. Sharma Post Graduate Institute of Medical Sciences, Rohtak.

\section{Dr. Kapil Yadav}

Junior Resident, Dept. of Community Medicine, Pt. B.D. Sharma Post Graduate Institute of Medical Sciences, Rohtak.

ABSTRACT Isolation is recommended for corona positive patients and their contacts are advised home quarantine. This study was planned to assess the practices followed during home quarantine/ isolation for COVID-19 pandemic among urban population in Rohtak, Haryana.

A cross-sectional survey was conducted among 101 persons on home isolation or quarantine in urban field practice areas attached to the Department of Community Medicine of a tertiary care centre of Rohtak. A semi-structured interview schedule was used to obtain information from the participants through house to house visit. Data were analysed using Microsoft Excel version 2010 and Statistical Package for Social Sciences ver.24

$79.2 \%$ subjects on home quarantine/ isolation restricted their movement inside house. Face cover was used by $98 \%$ and correct hand washing technique was practised by $70.3 \%$ participants. Behaviour change communication activities need to be further strengthened to improve practices followed during home quarantine/isolation.

\section{KEYWORDS : home, quarantine, isolation}

\section{INTRODUCTION}

The corona virus disease 2019 (COVID-19) is caused by a novel corona virus (SARS CoV-2). After originating from Wuhan (China) in December 2019, it has spread rapidly throughout the world. Due to this, the World Health Organization (WHO) declared this outbreak a Public Health Emergency of International Concern on January 30, 2020. [1] On 11 th March, WHO declared COVID-19 "a pandemic" as by then, about 114 countries were affected.[2]

COVID-19 presents with fever, cough, difficulty in breathing and other respiratory problems. This disease spreads from person to person through droplets from nose or mouth, expelled when a COVID-19 case coughs, sneezes or speaks. People can become infected by touching their eyes, nose or mouth after touching the surfaces having these droplets. [3]

As on September 15, 2020, India and Rohtak registered a total of 4,930,236 and 4,253 COVID-19 cases respectively. [4,5] The WHO and the Centers for Disease Control and Prevention advise those infected with or exposed to COVID-19 to isolate or quarantine at home in a separate room and use separate bathroom if possible $(6,7)$. Quarantine means "the restriction of activities and/or separation from others of suspect persons who are not ill in such a manner as to prevent the possible spread of infection or contamination."[8] Isolation is the separation of infected persons from others to prevent the spread of the virus[6].

The Ministry of Health and Family welfare (MoHFW) has issued guidelines related to home isolation and home quarantine in India. Despite all these efforts, there are gaps in following proper practices as per these guidelines by the people on home quarantine and isolation leading to further spread of this pandemic. There is paucity of research on the practical aspects of this subject in Haryana. Hence, this study was planned to assess the practices followed during home quarantine/ isolation period of COVID-19 pandemic among urban population in Rohtak, Haryana.

\section{MATERIAL AND METHODS}

It was a cross-sectional survey conducted among 101 persons on home isolation or quarantine from $1^{\text {st }}$ July to 3lst August, 2020 in urban field practice areas attached to the Department of Community Medicine of a tertiary care centre of Rohtak.

A semi-structured interview schedule, consisting of identification, socio-demographic details and questions related to practices followed during home quarantine and isolation period, was used to obtain information from the study participants through house to house visit.

\section{Inclusion Criteria:}

i) Those present at the time of home visit ii) Those willing to give informed consent for the study. The purpose of the study was explained to each participant by the investigator. Social distancing was maintained and personal protective measures were used while interviewing the subjects after obtaining informed consent.

\section{Statistical Analysis:}

Data were entered and analysed using Microsoft Excel version 2010 and Statistical Package for Social Sciences ver.24. The results were expressed as proportions.

\section{RESULTS}

Out of the study participants, $80.2 \%$ were contacts on home quarantine and $19.8 \%$ mild cases on home isolation. The mean age of subjects was $42.8 \pm 15.5$ years. $35.6 \%$ were males and $64.4 \%$ were females. 
Table 1: Distribution Of Study Participants According To Educational Status And Occupation

\begin{tabular}{|l|l|l|}
\hline Educational status & $\begin{array}{l}\text { Frequency } \\
(\mathbf{N}=101)\end{array}$ & $\begin{array}{l}\text { Percentage } \\
(\%)\end{array}$ \\
\hline Illiterate & 5 & 5.0 \\
\hline Primary & 9 & 8.9 \\
\hline Middle & 9 & 8.9 \\
\hline Secondary & 21 & 20.8 \\
\hline Senior secondary & 18 & 17.8 \\
\hline Graduate and above & 39 & 38.6 \\
\hline Occupation & & \\
\hline Unemployed/ Homemaker & 53 & 52.5 \\
\hline Service & 19 & 18.8 \\
\hline Business and self-employed & 18 & 17.8 \\
\hline Student & 10 & 9.9 \\
\hline Labourer & 1 & 1 \\
\hline
\end{tabular}

Table 1 demonstrates that $38.6 \%$ subjects had completed their graduation. More than half $(52.5 \%)$ of the subjects were unemployed or homemakers.

$88.1 \%$ participants were asymptomatic and $11.9 \%$ had mild symptoms. $96 \%$ subjects had history of contact with a COVID patient. Of these, $95.9 \%, 2.1 \%$ and $1 \%$ had contact with family member, workplace colleague and neighbour respectively.

Of the total respondents, $94.1 \%$ were staying in separate room during home quarantine/isolation period. $5.9 \%$ of the subjects were not staying in separate room; however, $83.3 \%$ of them maintained more than one metre distance with others. Ventilation was adequate in $97 \%$ of the rooms. Separate washroom facilities were available for $92.1 \%$ participants. Toilet surfaces were disinfected daily with household bleach or phenolic disinfectant in $96 \%$ of the households.

The correct technique of hand washing was known to $70.3 \%$ respondents and they washed their hands for 40 seconds or more.

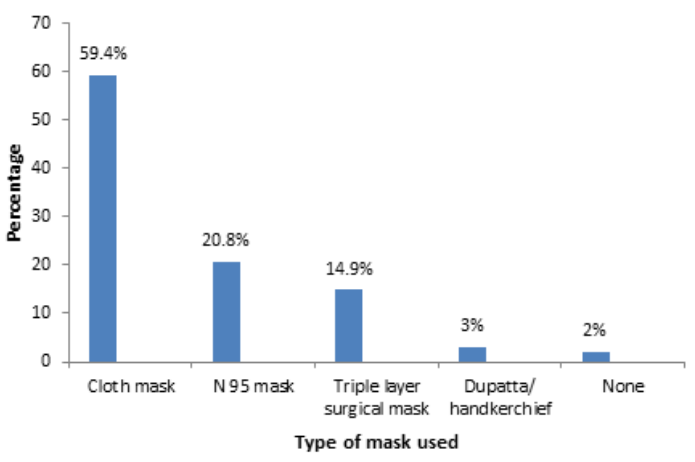

Figure 1: Bar Diagram Showing Distribution Of Study Subjects According To Type Of Mask Used

Figure 1 depicts that $59.4 \%$ of the subjects wore cloth mask, while, $2 \%$ did not cover their face at all.

About two-fifths (40.6\%) of the respondents were not wearing mask all the time. Of these, $51.2 \%$ did not consider it necessary, $34.2 \%$ had discomfort and $14.6 \%$ were ignorant. $43.6 \%$ subjects changed mask every 6 to 8 hours. $67.3 \%$ participants washed their mask, while, $30.7 \%$ discarded it in dustbin after use.

$90.1 \%$ participants knew whom to contact in case symptoms start appearing. Movement was restricted within the house among $79.2 \%$ participants. More than three-fourth (76.2\%) of the subjects were staying away from high risk groups (elderly, pregnant, kids, co-morbid). Religious or social gatherings were attended by $7.9 \%$ subjects. Visitors were coming inside houses of $5.9 \%$ respondents, while other family members of
$20.8 \%$ subjects were moving out of their homes during quarantine. $37.6 \%$ participants were sharing household items like dishes, glasses, towel or bedding. $6.9 \%$ and $5.9 \%$ subjects had difficulty in obtaining food items and medicines respectively.

$57.4 \%$ respondents were cared by one family member, while, $5.9 \%$ by two or more members. $36.7 \%$ subjects took self- care. While cleaning surfaces or handling soiled linen, $68.3 \%$ caretakers wore gloves. Surface disinfection in the room was done using $1 \%$ sodium hypochlorite by $20.8 \%$ subjects. However, phenolic disinfectants and sanitizers were used by $68.2 \%$ and $11 \%$ participants respectively. $98 \%$ subjects washed their clothes and linen separately using detergent.

$91.1 \%$ subjects were supervised by official machinery. Of these, $51.1 \%$ were supervised by doctors, while, $48.9 \%$ by health workers. The methods of supervision were phone calls, personal visits and both among $37 \%, 14.1 \%$ and $48.9 \%$ of the subjects respectively. Barricading was done outside $42.6 \%$ of the houses. Of these, barricading was done after more than a day of reporting positive case for $83.7 \%$ houses, while it was done in 6 to 24 hours and less than 6 hours for $14 \%$ and $2.3 \%$ houses respectively. It was done for 17 or more days in $76.1 \%$ of the houses. Sanitization was done outside $88.1 \%$ houses.

\section{DISCUSSION}

Of the total respondents, $94.1 \%$ were staying in separate room. Similar findings were reported by Li et al (2020) in China where $94.44 \%$ subjects on home isolation fully complied by staying in separate room.[9]

In the present study, $5.9 \%$ subjects were not staying in separate room during home quarantine/ isolation period. While, in a study conducted by Sehgal et al (2020) in United States (U.S.), isolation or quarantine was impossible in $20.8 \%$ of all U.S. residential units, because they lacked sufficient bedrooms, bathrooms or both [10].

Separate washroom facilities were available for $92.1 \%$ participants in the present study. However, only $22.22 \%$ subjects fully complied with using separate toilets in a study by Li et al (2020).

Movement was restricted within the house among $79.2 \%$ participants, while, it was $100 \%$ in a study by Li et al (2020)[9]. $20.8 \%$ subjects were moving out of their homes during quarantine/ isolation period. However, in a Japanese study by Machida et al (2020), 82.9\% participants, who experienced cold-like symptoms within 7 days of symptom onset amid COVID-19 outbreak, went out of their homes for reasons other than hospital visits. [1 1]

Only one family member was taking care for $57.4 \%$ of the subjects in the current study. However, it was $71.3 \%$ in a study by Li et al (2020)[9]. The present study showed that $98 \%$ of the respondents used face cover, whereas, $93.52 \%$ subjects used masks in a study by Li et al (2020)[9]. MoHFW recommends that the home isolated persons should wear triple layer surgical masks[12], while, $59.4 \%$ subjects were using washable cloth masks in this study.

The quarantined people should be placed in well ventilated rooms with fresh and clean outdoor air to control contaminants and odours.[13] In view of this, ventilation was adequate in $97 \%$ of the rooms. $70.3 \%$ subjects practised the correct technique of hand washing which is an important infection prevention and control measure.

\section{CONCLUSION}

Among the home quarantined/ isolated subjects, 79.2\% restricted their movement inside house. Face cover was used by $98 \%$ and correct hand washing technique was practised by 
$70.3 \%$ participants. Behaviour change communication activities need to be further strengthened to improve practices followed during home quarantine/isolation.

\section{REFERENCES}

1. World Health Organization. (2020, January 30). Statement on the second meeting of the International Health Regulations (2005) Emergency Committee regarding the outbreak of novel coronavirus (2019. nCoV).Retrieved September 1,2020, from https://www.who.int/newsroom/detail/30-01-2020-statement-on-the-second-meeting-of-theinternational-healthregulations-(2005)-emergency-committee-regardingthe-outbreak-of-novelcoronavirus-(2019-ncov)

2. World Health Organization. (2020). Rolling Updates on Coronavirus Disease (COVID-19). Retrieved September 1, 2020, from https://www.who.int/ emergencies/diseases/novel-coronavirus-2019/events-as-they-happen

3. World Health Organization. (2020, April 17). Q\&A on coronaviruses (COVID19). Retrieved September 5, 2020, from https://www.who.int/emergencies/ diseases/novel-coronavirus-2019/question-and-answers-hub/q-a-detail/qacoronaviruses

4. Ministry of Health and Family Welfare. (2020, September 15). COVID-19 INDIA as on: 15 September 2020, 08:00 IST. Retrieved September 15, 2020, from https://www.mohfw.gov.in/

5. District Wise COVID-19 Cases. Retrieved September 15, 2020, from https://covidindia.org/haryana/

6. World Health Organization (2020, March 19). Considerations for quarantine of individuals in the context of containment for coronavirus disease (COVID19). Accessed at www.who.int/publications-detail/considerations-forquarantine-of-individuals-in-the-context-of-containment-for-coronavirusdisease-(covid-19) on 12 September 2020.

7. Centers for Disease Control and Prevention. COVID-19 Isolate if you are sick. Accessed at https://www.cdc.gov/coronavirus/2019-ncov/if-you-aresick/isolation.html on 12 September 2020

8. International Health Regulations (2005) Third edition. 2016. Geneva: World Health Organization; 2020. (https://www.who.int/ihr/ publications/ 9789241580496/en/accessed 12 September 2020)

9. Li, H., Peng, Y.Y., \& Lu, J.P. (2020). Investigation and Analysis of 108 Cases of Home Isolated Patients with Mild COVID-19. Disaster Medicine and Public Health Preparedness. https://www.cambridge.org/core/services/aopcambridge-core/content/view/36AA6543B40C979F4891E0DCC53BF9AE/ S1935789320002967a.pdf/investigation and analysis of 108 cases of ho me_isolated_patients_with_mild_covid 19 9.pdf

10. Sehgal, A.R., Himmelstein, D.U., \& Woolhandler, S. (2020). Feasibility of Separate Rooms for Home Isolation and Quarantine for COVID-19 in the United States. Annals of Internal Medicine. https://www.ncbi.nlm.nih.gov/ pmc/articles/PMC7392146/

11. Machida, M., Nakamura, I., Saito, R., Nakaya, T., Hanibuchi, T., Takamiyal,T., Odagiri, Y., Fukushima, N., Kikuchi, H., Amagasa, S., Kojima, T., Watanabe, H., \& Inouel, S. (2020). The actual implementation status of self-isolation among Japanese workers during the COVID-19 outbreak. Tropical Medicine and Health, 48(63). https://doi.org/10.1186/s41182-020-00250-7

12. Ministry of Health and Family Welfare.(2020, July 2). Revised guidelines for Home Isolation of very mild/pre-symptomatic/asymptomatic COVID-19 cases. Retrieved September 14,2020, from https://www.mohfw.gov.in/pdf/ RevisedHomeIsolationGuidelines.pdf

13. World Health Organization. (2020. August 19). Considerations for quarantine of contacts of COVID-19 cases: Interim guidance. Retrieved September 15 , 2020 from https://apps.who.int/iris/bitstream/handle/10665/333901/WHO2019-nCoV-IHR_Quarantine-2020.3-eng.pdf? sequence = 1 \&isAllowed $=\mathrm{y}$ 